\section{Biliary Tract Obstruction by Unusual Parasites}

A 30-year-old Indonesian woman, who had habitually eaten raw fish since childhood. presented with biliary pain. jaundice, and fever. She had had several similar episodes in the past, looked ill and icteric. and was febrile, with tenderness in the right hypochondriac region.

Significant laboratory findings were leukocytosis of $30,000 / \mathrm{mm}^{3}$ with $80 \%$ neutrophils, and serum bilirubin of $6.1 \mathrm{mg} / \mathrm{dl}$ with raised liver enzymes. Sonography showed a dilated $(20 \mathrm{~mm})$ and thickened common duct with echogenic foci. On the CT, peripherally situated, tortuous, hypoattenuated lesions were seen in both lobes of the liver, characteristic of hepatic fascioliasis (1). Linear, irregular, and rounded filling defects in the dilated common bile duct were the striking features on endoscopic retrograde cholangiopancreatography (Figure 1). A papillotomy was carried out, and three worms and several stones were extracted. One of the worms was a Fasciola gigantica measuring $8 \mathrm{~cm} \times 2 \mathrm{~cm}$, which was fleshy-looking and resembled a leaf rolled up along its long axis. Typical large, ovoid, operculated, brown. bile-stained ova were seen within the worm (2). The other two helminths were identified as Physaloptera caucasica (Figure 2). One was fragmented during extraction. The intact worm measured $85 \mathrm{~mm} \times 3 \mathrm{~mm}$. with a sharply pointed posterior end. The anterior end had two large lips armed with two papillae, rows of dental processes, and an integumentary collarette around the head (3). This feature differentiated it from an ascaris. The typical embryonic eggs were seen within the worms, in the stools, and at the center of the bile duct calculi.

Antibiotic treatment was initiated, with praziquantel being used to treat Fasciola gigantica and diethylcarbamazine for Physaloptera caucasica (3.4). A repeat sonography showed normal biliary radicles, and the patient was well eight months after discharge.

Q. Q. Contractor, K.S. Al Hamid, A.M.M.K. Farrag, I. ul Haque Depts, of Medicine, Surgery, and Laboratory Medicine, King Fahd Specialist Hospital, Buraydah, Saudi Arabia

\section{References}

1. Beers BV, Pringot J, Geubel A, Trigaux JP, Bigaignon G, Dooms G. Hepatobiliary fascioliasis: noninvasive imaging findings. Radiology 1990; 174: 809-10.

2. Manson-Bahr PEC. Bell DR. Manson's tropical diseases London: Baillière Tindall, 1989: 486-95.

3. Beaver PC. Jung RC. Cupp EW. Clinical parasitology, 9 th ed. Philadelphia: Lea and Febiger. 1984:343-4.

4. Al Teimi IN. Biliary fascioliasis: clinical spectrum and endoscopic management. Saudi J Gastroenterol 1995: 1:4751.

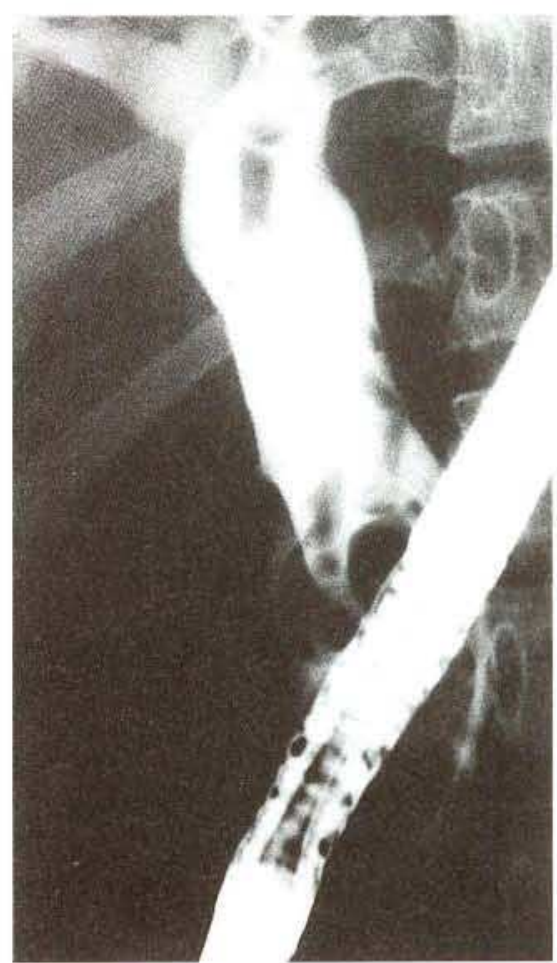

Figure 1: Linear, irregular and rounded filling defects seen in a dilated common bile duct on endoscopic retrograde cholangiopancreatography. caused by unusual parasites and calcult.

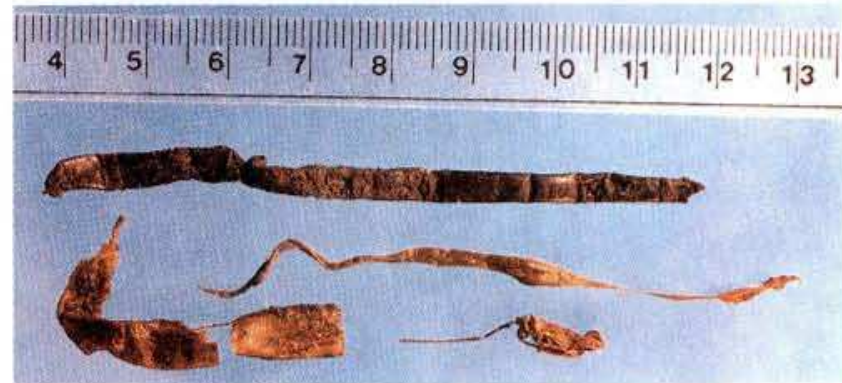

Figure 2: Physaloptera caucasica, resembling an immature ascaris.

Corresponding Author

Q. Q. Contractor, M.D.

P.O. Box 2290

King Fahd Specialist Hospital

Gassim

Buraydah

Saudi Arabia

Fax:+966-6-3244895 